\title{
Greek polydefinites revisited
}

\section{Polydefiniteness as resumed relative clause modification}

\author{
Evripidis Tsiakmakis | ORCID: 0000-0001-6799-7894 \\ Universitat Autònoma de Barcelona, Barcelona, Spain \\ Evripidis.Tsiakmakis@uab.cat
}

Joan Borràs-Comes | ORCID: 0000-0002-2855-7340

Universitat Autònoma de Barcelona, Barcelona, Spain

joanborrascomes@gmail.com

\author{
M.Teresa Espinal | ORCID: 0000-0002-8079-7253 \\ Universitat Autònoma de Barcelona, Barcelona, Spain \\ Teresa.Espinal@uab.cat
}

\begin{abstract}
This article focuses on the interpretation of the adjectives that appear in Greek polydefinite DPs. It provides empirical support to the established position that restrictive modifiers are preferred in polydefinite environments (Kolliakou 1995). At the same time, it shows that non-restrictively modified polydefinites are not excluded by grammar (Manolessou 2000). To reconcile the facts, a novel syntactic analysis of polydefiniteness as involving modification by either restrictive or non-restrictive reduced relative clauses is formulated. We extend Alexopoulou's (2006) analysis of resumption in full relatives to polydefinites and defend that what looks like a preadjectival definite article is a resumptive clitic pronoun that values the unvalued definiteness feature of a null relative complementizer. We further defend that, while the prenominal definite article is interpreted as d-linked, the resumptive clitic is a dependent expression that is interpreted as a referentially bound anaphora.
\end{abstract}

\section{Keywords}

polydefinites - Greek - (non-)restrictive relative clauses - resumption

(C) EVRIPIDIS TSIAKMAKIS, JOAN BORRÀS-COMES AND M.TERESA ESPINAL, 
The possibility of spreading of the definite determiner (Androutsopoulou 1995) within the Greek DP sparked linguists' interest already in the mid-1980s (Horrocks \& Stavrou 1986). Since then, many researchers have taken pains to solve what could be subsumed under the term polydefiniteness challenge (Kolliakou 1995, 2004; Alexiadou \& Wilder 1998; Campos \& Stavrou 2004; Lekakou \& Szendrői 2007, 2012; Alexiadou 2014; Guardiano \& Stavrou 2019, among others). This substantial amount of work allowed for the identification of the core properties that are associated with this grammatical phenomenon: Greek polydefinite DPs have colloquial status (Mackridge 1985; Manolessou 200o), they contain definite determiners that do not independently introduce iota functions (in the sense of Sharvy 1980), they are subject to Heim's (1982) Prominence Condition, in that they can pick their referents only anaphorically and not associatively (Tsakali 2008; Alexiadou 2014), and they mostly concern predicative modifiers that are interpreted restrictively (Kolliakou 1995, 2004; Alexiadou \& Wilder 1998; Campos \& Stavrou 2004; Lekakou \& Szendrői 2007, 2012).

In the present paper, we focus on the last of the above-mentioned properties. While most researchers take the restrictive reading of the modifying element to be an essential property of polydefiniteness, there are studies (Manolessou 20oo; Panagiotidis \& Marinis 2011) pointing to polydefinite examples involving non-restrictively interpreted adjectives. There have been some attempts to speculatively address this latent debate. Lekakou \& Szendröi (2012) suggest that non-restrictively modified polydefinite DPs are either exceptional or coerce a restrictive reading of the adjective involved, while Alexiadou (2014) proposes that the restrictiveness parameter of polydefiniteness is subject to dialectal variation. We attempt, for the first time to our knowledge, an evidence-based answer to the question.

Specifically, we present the results of an experimental study designed to test the existence and strength of a restrictiveness constraint in Greek polydefiniteness. Based on these results, showing an extremely strong but not absolute preference for restrictive over non-restrictive modifiers as parts of polydefinite DPs, we suggest that what emerges as a polydefinite DP in Greek can have a dual source: the indirect modification of a definite nominal by either a restrictively or a non-restrictively interpreted modifier.

This idea is fleshed out by providing a novel syntactic analysis of Greek polydefinite DP s. Building on existing insights (Alexiadou \& Wilder 1998; Alexiadou 2014; Giusti 2015), polydefiniteness is analyzed as a type of postnominal modification in the form of a reduced relative clause. We depart from previous accounts in proposing that reduced relatives of the polydefiniteness type 
can be restrictive or non-restrictive and display resumption in a way parallel to full relatives (Alexopoulou 2006). By allowing for both types of relatives, we account for the set of data we have collected. By introducing resumption into the analysis, we bring polydefinites close to clitic left dislocation constructions (Anagnostopoulou 1994). In this way, we indirectly predict that they are d-linked expressions whose multiple determiners display some sort of referential dependency. The Prominence constraint to which polydefinites have been argued to be subject (Tsakali 2008; Alexiadou 2014) may be an epiphenomenon derived from the interaction between their d-linkhood and morphological definiteness.

The rest of the article is organized as follows. Section 2 is a presentation of the data under investigation, the main properties of polydefiniteness and the basic problem to be addressed, namely the interpretation of adjectives in polydefinite environments. Section 3 is devoted to the experiment that we conducted. It includes a detailed description of the results obtained and their interpretation. In Section 4, we navigate through the most influential (families of) analyses of polydefinite DPs, to finally end up with our own proposal. We then conclude in Section 5 with some of the implications of our analysis.

2.1 The shape of polydefinites

Greek polydefinite DP s seem to differ minimally from their standard definite equivalents—called monodefinite here—in displaying doubling of the definite determiner. ${ }^{1}$
(1) a. to ksilino trapezi
the wooden table
'the wooden table'
b. to ksilino to trapezi
the wooden the table
'the wooden table'

1 In the present paper, Greek polydefinite DPs are studied in isolation and no claim is made regarding polydefinites in other languages such as Hebrew, Albanian, Norwegian or Romanian. See Velegrakis (2011) and Alexiadou (2014) for arguments against a common analysis for Greek determiner spreading and Persian ezafe constructions. 
However, there is more to polydefiniteness than implied in (1) above. First, it allows adjectives to surface postnominally, a possibility that leads to ungrammaticality in monodefinite DPs. Observe the contrast in (2).

(2) a. *to trapezi ksilino

the table wooden

b. to trapezi to ksilino

the table the wooden

'the wooden table'

Moreover, it can be manifested as complete (3a) or partial $(3 b)$ spreading of the definite determiner along a multiply modified DP. ${ }^{2}$

(3) a. to meghalo to ksilino to trapezi

the big the wooden the table

'the big wooden table'

b. to meghalo to ksilino trapezi

the big the wooden table

'the big wooden table'

What is more, polydefiniteness grants freedom of constituent order within the DP. The noun and its modifiers can appear in all possible orderings, the only restriction being that every postnominal adjective must be preceded by its own determiner.

(4) a. to palio to trapezi to ksilino the old the table the wooden 'the old wooden table'

b. to palio to ksilino to trapezi the old the wooden the table 'the old wooden table'

c. to trapezi to palio to ksilino the table the old the wooden 'the old wooden table'

2 Stavrou (1995) and Alexiadou \& Wilder (1998) note that cases of partial definiteness spreading are marked but still accepted by Greek speakers. 
d. to palio trapezi to ksilino the old table the wooden 'the old wooden table'

e. to palio to ksilino trapezi the old the wooden table 'the old wooden table'

f. *to palio to trapezi ksilino the old the table wooden

One last comment is in order. While Greek does not seem to obey as strict an adjective hierarchy as the one proposed for other languages (Holton et al. 1997), some orders sound more natural than others. When polydefiniteness emerges, this asymmetry disappears (Alexiadou et al. 2007). Notice the contrast between

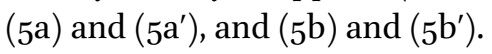

\section{(5) a. to kenurghio kokino trapezi \\ the new red table \\ 'the new red table'}

a'. to kenurghio to kokino to trapezi

the new the red the table

'the new red table'

b. ?to kokino kenurghio trapezi

the red new table

'the new red table'

$\mathrm{b}^{\prime}$.to kokino to kenurghio to trapezi

the red the new the table

'the new red table'

In the examples that follow, all different orders of constituents, restricted in the ways stated above, are possible. For reasons of space, we do not provide an exhaustive paradigm of the polydefinite DPs in the examples, unless necessary. 


\subsection{The essence of polydefinites}

Greek polydefinite DPs differ from their monodefinite counterparts not only externally, in the ways suggested in the previous subsection, but also in more profound ways. The aim of this section is to briefly present the core properties of polydefiniteness, as they have been identified by the previous literature on the topic.

To begin with, polydefinites have a colloquial status in Modern Greek (Mackridge 1985; Manolessou 200o; Panagiotidis \& Marinis 2011; Guardiano \& Stavrou 2019). Example (6) that follows is more likely to be uttered from a lab researcher to her colleague than written in a lab methodology textbook.

\section{(6) Tora to dhighma prepi na bi sto dhoxio to now the sample must to be-put at-the recipient the apostiromeno. sterilized \\ 'Now the sample must be put in the sterilized recipient'.}

Manolessou (2000) weakly associates this property with an affectiveness element present in some polydefinite DP s. No matter what its source is, the colloquial nature of polydefinites has to do with their interpretation at levels higher than the phrasal or even the sentential one. Therefore, it is not discussed any further here. ${ }^{3}$

The second characteristic of polydefiniteness concerns the reference potential of the multiple determiners that emerge within the same DP. By standard assumptions, definite determiners are associated with the introduction of an iota operator (Partee 1987; Sharvy 1980): they allow reference to the unique object or the maximal set of objects denoted by the noun. However, the doubled determiners that arise in polydefinite DPs do not independently pick discourse-referents. As the agreement data in (7) suggest, the whole polydefinite DP makes reference to a single entity, namely the unique white sheet in the context (see also Lekakou \& Szendrői 2012). ${ }^{4}$

3 See Tsiakmakis et al. (to appear) for experimental evidence that supports the hypothesis that Greek polydefinites are subject to an informal-register constraint and that Greek polydefinites are expressive variants of their simple definite counterparts, expressing some kind of closeness of the speaker to the addressee. See also Marmaridou (1984) on the link between Greek proper name polydefinite DPs and familiarity.

4 See Espinal (to appear) for the hypothesis that expletive articles encode not the operation function associated with iota (according to which D shifts the semantic type of its nominal complement from a property $\langle\mathrm{e}, \mathrm{t}\rangle$ to an entity $\langle\mathrm{e}\rangle$; Russell 1905; Partee 1987), but rather an identity function that maps functions of type $\mathrm{T}$ onto functions of type $\mathrm{T}$ (type $\langle\mathrm{T}, \mathrm{T}\rangle)$. 

(7) To sedoni to aspro plithike / $/$ plithikan xthes. the sheet the white was-washed were-washed yesterday 'The white sheet was washed yesterday.'

The ungrammaticality of a plural verb in (7) can be interpreted in two different ways: either the second determiner is referentially inert, or it is obligatorily coreferential with the first one. In either case the verb must show singular number agreement.

There is another identifying property of Greek polydefinite DP s that relates to their discourse-referent picking capacity. Similar to doubled DPs in clitic doubling constructions in the verbal domain (Anagnostopoulou 1994), polydefinites are claimed to be subject to Heim's (1982) Prominence Condition (Tsakali 2008; Alexiadou 2014): In contrast with monodefinites, and similarly to personal pronouns, polydefinite DPs cannot pick their referent associatively, but only anaphorically. Let us make this clearer with an example.

a. I Katerina dhjavase ena vivlio ya tin Agela Kastrinaki ${ }_{i}$ ke the Katerina read a book for the Agela Kastrinaki and thelise na epikinonisi me ti dhiasimi singrafe $a_{i j}$ wanted to communicate with the famous author tilefonika. phone-ADV

'Katerina read a book about Agela Kastrinaki and wanted to reach the famous author via phone'.

b. I Katerina dhjavase ena vivlio ya tin Agela Kastrinaki $i_{i} k e$ the Katerina read a book for the Agela Kastrinaki and thelise na epikinonisi me ti dhiasimi ti singrafea $_{i / \# j}$ wanted to communicate with the famous the author tilefonika. phone-ADV 'Katerina read a book about Agela Kastrinaki and wanted to reach the famous author via phone'.

The examples in (8) are adapted from Tsakali (2008) and are meant to illustrate the interpretative asymmetry between a monodefinite DP and its polydefinite counterpart. While the monodefinite ti dhiasimi singrafea in (8a) is ambiguous in that it can refer either to Agela Kastrinaki or the author of the book that Katerina read, its polydefinite counterpart only displays the former option. Being subject to the Prominence Condition, ti dhiasimi ti singrafea can refer 
anaphorically to Agela Kastrinaki, but it cannot associatively pick the author of the book as its referent. Putting it in an informal way, polydefinite DPs are strictly definite nominal expressions.

The last core property of polydefiniteness that needs to be mentioned is that it allegedly concerns only a specific type of adjectival modification. Since this property is at the center of our study, it is presented in detail in the following subsection.

\subsection{What makes a good polydefiniteness candidate?}

Early studies on Greek polydefiniteness (Alexiadou \& Wilder 1998; Manolessou 2000; Campos \& Stavrou 2004) observe that only adjectives that can be used predicatively arise in polydefinite DPs. Notice the contrast between (9) and (10). The adjective for careless, which appears in copular constructions, is compatible with polydefiniteness. The Greek equivalent of alleged, though, is not an appropriate copula complement and does not make a good polydefiniteness candidate.

(9) a. $O$ dholofonos ine epipoleos. the murderer is careless 'The murderer is careless.'

b. $o$ epipoleos $o$ dholofonos the careless the murderer 'the careless murderer'

(10) a. \#O dholofonos ine ipotithemenos.

the murderer is alleged

'The murderer is alleged'.

$$
\begin{aligned}
& \text { b. \#o ipotithemenos o dholofonos } \\
& \text { the alleged the murderer } \\
& \text { 'the alleged murderer' }
\end{aligned}
$$

However, it is also noted that a predicative source is a necessary but not sufficient condition for an adjective to surface as the articled modifier of a polydefinite DP (Manolessou 2000; Alexiadou et al. 2007; Alexiadou 2014).

(11) a. I apotixia ine pithani. the failure is probable 'The failure is probable'. 


\section{b. \#i apotixia $i$ pithani \\ the failure the probable \\ 'the probable failure'}

(12) a. I parastasi itan katapliktiki.

the show was amazing

'The show was amazing.'
b. \#i parastasi $i$ katapliktiki
the show the amazing
'the amazing show'

Example (11) involves a modal adjective and example (12) contains a subjective evaluative adjective. While both are fine in copular sentences, neither is appropriate in a polydefinite environment. Data like these have been regarded as evidence that the articled modifiers that arise in Greek polydefinites should have a predicative source and, furthermore, be interpreted intersectively. It is this second condition that explains the reduced acceptability of (11b) and (12b), as contrasted with $(9 \mathrm{~b})$.

Additional evidence for the strong link between polydefiniteness and modifier intersectivity comes from adjectives that are in general ambiguous between a predicate-modifying and a nominal-modifying interpretation (Larson 1995, 1998).

(13) a. $O$ oreos traghudhistis apoxorise apo to sou. the nice singer left from the show 'The singer \{who is nice, who sings nicely\} left the show.'

b. $O$ traghudhistis o oreos apoxorise apo to sou. the singer the nice left from the show 'The singer who is nice left the show.'

As suggested by the translations provided above, oreos in (13a) may modify either the singer who left the show or an abstract singing event. Polydefiniteness in (13b), however, cancels the latter alternative (Alexiadou et al. 2007; Stavrou 2012, 2013).

Kolliakou $(1995,2004)$ introduces a third property that an adjective should have to be licensed as part of a polydefinite DP: the capacity to function as a restrictive modifier. She observes that, while in monodefinite DPs adjectives can be interpreted either restrictively or non-restrictively, only the former option is available for those contained in polydefinites. 
(14) a. I dhiefthindria apofasise $i$ atakti mathites na epanalavun the principal decided the naughty students to repeat tin eksetasi. the exam 'The principal decided that the naughty students will repeat the exam.'

b. I dhiefthindria apofasise $i$ atakti $i$ mathites na the principal decided the naughty the students to epanalavun tin eksetasi. repeat the exam 'The principal decided that the naughty students will repeat the exam.'

Example (14b) contains the polydefinite DP $i$ atakti $i$ mathites and therefore it is interpreted as follows: The principal of the school decided that only those students who misbehave will take the exam again. On the other hand, the monodefinite iatakti mathites in (14a) makes it ambiguous. It can also mean that all the students are naughty and (therefore) the principal decided that they will all repeat the exam.

Before we proceed, two clarifications need to be made. Kolliakou phrases her Polydefiniteness Constraint as follows: "Greek polydefinites are unambiguously non-monotone anaphoric expressions: the discourse referent $\mathrm{Y}$ of a polydefinite is anaphoric to an antecedent discourse referent $X$, such that $Y \subset X$ " (Kolliakou 2004: 273). Notice that the restrictiveness of polydefinites, as highlighted by Kolliakou $(1995,2004)$ and taken up by the generative literature on the topic (Alexiadou \& Wilder 1998; Campos \& Stavrou 2004; Lekakou \& Szendrői 2012; Alexiadou 2014), is defined as the intersective and restrictive interpretation of the articled modifiers that appear within a polydefinite DP. Notice also that Kolliakou (2004) derives the restrictive interpretation of adjectives from the discourse properties of polydefinite DP s. On the contrary, at least some of the generative analyses of the phenomenon introduce the restrictiveness of the modifier into the syntactic representation. The relevance of these comments is crucial for the interpretation of the results of the experimental study to be presented in the following section.

Recapitulating what has been said so far, those adjectives that emerge as articled modifiers within polydefinite DPs have a predicative source and are interpreted intersectively and restrictively: They enter the derivation embedded under a predicative structure of some sort, they denote a set that intersects with the set denoted by the noun and the intersection of the two sets is a subset of the already established in the discourse set to which the whole polydefinite DP anaphorically refers (Alexiadou et al. 2007). 
Most of the analyses of polydefiniteness put forth in the literature assume that all these three properties are intrinsic to the phenomenon and have come up with different mechanisms to derive them directly or indirectly. However, Manolessou (2000) and Panagiotidis and Marinis (2011) warn that polydefiniteness can arise even in contexts where the adjective is not supposed to be interpreted restrictively.

(15) Kalos ta palikaria ta omorfa! welcome the lads the handsome 'Hello, guys!'

(16) Ton varese o krios o aeras kai sinilthe. him hit the cold the air and came-round 'The cold air hit him and he came round.'

Examples such as (15) and (16) can be felicitously uttered even when there are neither ugly lads nor hot air present in the discourse. Examples like these are interesting because they have given rise to a subtle debate. On the one hand, there are researchers who consider the restrictive interpretation of the adjective an integral part of polydefiniteness. For them, non-restrictively modified DPs either involve coercion of a restrictive reading of the modifier (Lekakou \& Szendrői 2012) or constitute cases that should be kept apart from polydefiniteness proper (Lekakou \& Szendrői 2012; Alexiadou 2014; Giusti 2015). On the other hand, some suggest that restrictiveness is only indirectly related to polydefiniteness (Manolessou 2000) and thus a unifying account of the phenomenon can be maintained.

In view of this open end, we set out to find how the relationship between restrictively and non-restrictively modified polydefinites should be captured. Given the lack of empirical studies related to polydefiniteness in Modern Greek, we decided to conduct an experimental study that would provide linguistic evidence for the relation that polydefiniteness bears to restrictive modification. The study is described in detail in the next section.

\section{The experimental study}

An offline acceptability judgment task (see Schütze \& Sprouse 2014; Ionin \& Zyzik 2014; Juzek 2016) was designed to empirically test the hypothesis in (17), advocated for in the literature several times (Kolliakou 1995, 2004; Alexiadou \& Wilder 1998; Alexiadou et al. 2007; Lekakou \& Szendrői 2012; Alexiadou 2014, among others): 
(17) The restrictive interpretation of the adjective is a characteristic property of Greek polydefiniteness.

To this end, the monodefinite-polydefinite distinction was checked against restrictively and non-restrictively modified DPs.

The syntactic position of the definite DP was introduced as an extra parameter. We wanted to make sure that the structural proximity of a polydefinite to the main verb does not interact meaningfully with the acceptability of the former. Thus, (poly)definiteness was further checked against the subject vs. object distinction. ${ }^{5}$

\subsection{Method}

Participants were presented with recorded question-answer pairs that were performed by native Greek speakers. ${ }^{6}$ This recorded dialogue format was chosen in order to create the sense of spoken speech communication, given the colloquial status of the phenomenon under study. We asked participants to rate how natural each answer sounded as a follow-up to its respective question. The survey was administered via SurveyGizmo.

\subsection{Participants}

123 people volunteered to take part in the experiment. However, in the results section we only report the responses of 77 participants (20 male, 57 female; mean age 28.87 years, $\mathrm{SD}=10.36$ ), because the remaining 46 failed to complete the task. All participants had Greek as their native language; 67 of them $(87 \%)$ reported that Greek is their major language in everyday communication (daily use $>75 \%)$ and 59 of them $(76.6 \%)$ self-assessed their command of Greek as higher than $75 \%$. The participants were recruited via Facebook and other social media platforms.

\subsection{Materials}

For the materials of the experiment we used 5 modifiers that can be easily interpreted restrictively (kokinos 'red', meghalos 'big', xondros 'fat'/'thick', oreos 'beautiful', dhermatinos 'leather') and 5 modifiers that usually get a non-

5 The experiment was carried out following the regulations of the Ethics Committee on Animal and Human Experimentation of the Universitat Autònoma de Barcelona, under the approved experimental protocol CEEAH-4442.

6 We thank Anna Kampanarou and Maria Konstandinidou for lending their voices to the experiment. 
restrictive reading (feromenos 'alleged', ipotithemenos 'supposed', proin 'former', elinikos 'Greek' ekpliktikos 'amazing'). Notice that the second group consists of three privative, one relational and one subjective evaluative adjective. These adjectives are, according to standard literature, non-intersective and, thus, were considered to be among the best candidates to violate the restrictiveness constraint, as elaborated in Section 2.3.

Each modifier appeared as part of two monodefinite DPs and two polydefinite DP s, generating a total of 40 experimental items. We kept the constituent order of polydefinites consistent:DET+NOUN+DET+ADJ. Finally, we introduced the syntactic position parameter. Half of the monodefinite and half of the polydefinite DPs were construed as subjects. The remaining halves were in object position.

Each test-DP was presented to the participants as a response to a who-, which- or what-question, forming a short dialogue (see the Appendix for the complete list of experimental items). These $w h$-words created different discourse conditions for the interpretation of the answer-DPs. Manipulating the information structure allowed us to pry into the more grammatical aspects of polydefiniteness. No further contextual information was provided. There follow two examples from the list of materials, translated in English.

(18) Q: Ti se siginise pio poli? what you moved more much 'What moved you the most?'

A: I ekpliktiki erminia. the amazing performance 'The amazing performance.'

(19) Q: Ti thimase apo ti vradhia ton vravion? what remember-2SG from the night of-the awards 'What do you remember from the night of the awards?'

A: Tin atmosfera tin ekpliktiki. the atmosphere the amazing 'The amazing atmosphere.'

The answer in both (18) and (19) features the prototypically non-restrictive adjective amazing. However, while (18A) is a monodefinite DP, (19A) is a polydefinite. According to our hypothesis (17), it is predicted that the latter will be rated lower than (18A). Notice further that the answer-DP of (18) is syntactically 
a subject while $(19 \mathrm{~A})$ is an object. Given that this syntactic asymmetry has not been argued to interact with polydefiniteness, we predict that it will not affect the relative rating of the two answer-DPs in the above examples.

Apart from the experimental items, an additional set of 20 question-answer pairs were used as distractors. They were formulated as when-, where- or howquestions answered either with DPs of the sort DET+NOUN or PPs of the type PREP+DET+NOUN (see the set of materials in the Appendix). The answers to the filler questions did not include modifiers so there could be no competition between a monodefinite and a polydefinite DP.

We gave participants the following instructions: "Now, you will listen to a set of mini-dialogues, which are divided into a question and an answer. After listening to each mini-dialogue, a scale will appear on your screen from totally unnatural to absolutely natural. We ask you to use that scale to rate how natural each reply is to the respective question."

Participants rated the full set of items, producing 6o ratings each. Excluding the fillers, a total of 3,080 responses ( 77 participants $\times 40$ test items) were statistically analyzed.

\subsection{Procedure}

Participants completed the experiment using their own computers. First, they read the instructions. Then, they were asked to fill in a brief questionnaire concerning their sociolinguistic background (date of birth, gender, level of education, place of residence during childhood, actual place of residence, affiliation with linguistics or philological studies, competence level in Greek, percentage of daily use of Greek and self-evaluation of their competence in Greek; see the Appendix). After that, the main task started. Different randomized versions of the list of materials were presented to participants. Each item consisted of an audio file containing the mini-dialogue and a rating scale. Below an example of what participants saw is provided, translated into English.

(20) [Which cat gave birth? The cat the fat.] totally unnatural absolutely natural

As illustrated in (20), participants had to click on the audio symbol to hear the dialogue. Under this symbol, there appeared the scale: a left-to-right slide bar with a pointer at the center of the continuum. They had to move that pointer to any point of that continuum, without being informed about the exact value stored for each one of their responses. In this way, the participants' answers were recorded in a o to 100 scale, allowing the researchers to treat the depen- 


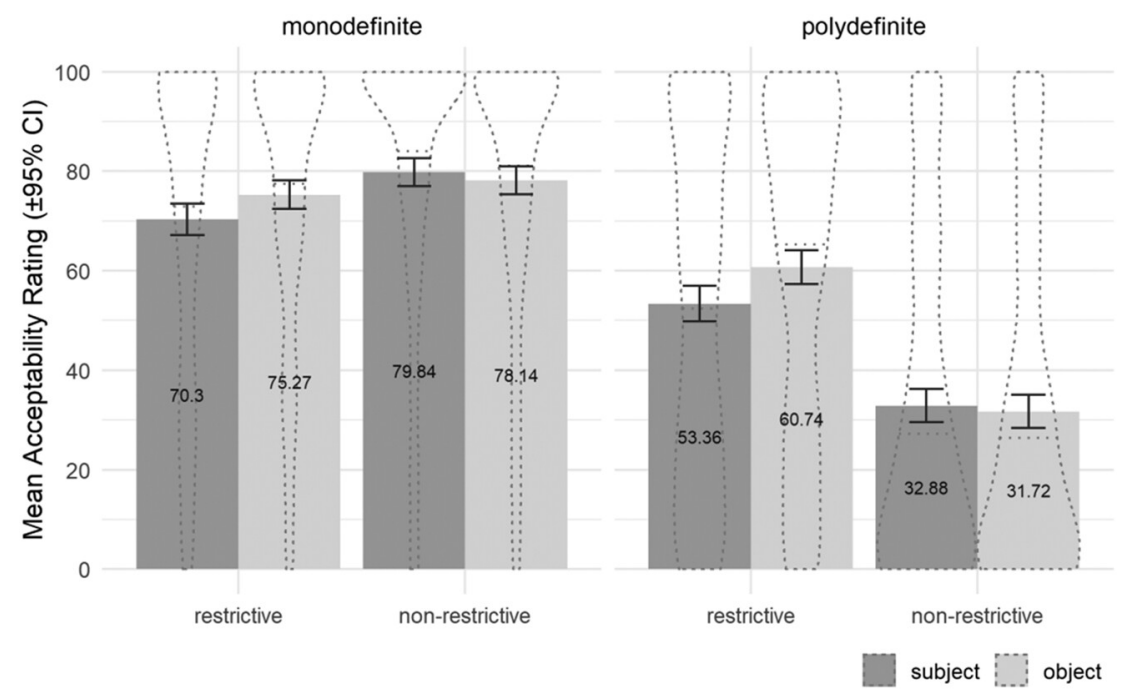

FIGURE 1 Results: definiteness $\times$ restrictiveness $\times$ position

dent variable in a more fine-grained scale than the ones obtained through, e.g., a 5 or a 7 -point Likert scale.

The median duration of the experiment was $15^{\prime} 27^{\prime \prime}$.

\subsection{Results}

The results of the experiment, as a function of Definiteness (Monodefinite, Polydefinite), Restrictiveness (Restrictive, non-Restrictive) and Position (Subject, Object), are summarized in Figure 1. A set of dotted-contour violin plots show the underlying distribution of the data and the location of the median value. The two levels of Definiteness are specified on top of the graph, the two Restrictiveness values appear in the $x$-axis and the two values of Position are depicted as two different tones of grey.

Figure 1 shows that native Greek speakers have a general preference for monodefinite over polydefinite DPs: while monodefinites have a mean acceptability rate around $75 \%$, the mean rating of polydefinites is $\leq 60 \%$. Restrictiveness seems to play a role only in the case of polydefiniteness. Restrictively modified polydefinite DPs are strongly preferred over non-restrictively modified ones. Finally, Position appears to have an unclear role, maybe relevant only for those DPs that contain restrictive modifiers.

The $g$ lmmTMB package in $\mathrm{R}$ was used for the analysis of the data obtained from the experiment. A generalized linear mixed-effects model was run, with the speakers' judgment as the dependent variable. The independent variables, Definiteness, Position, Restrictiveness, and all their possible interactions were 
set as fixed factors. Concerning the random factors, the model included a random slope for Definiteness and Restrictiveness by subject, a random slope for Position by subject, and a random intercept for Item. Model selection was performed by means of the package performance in $\mathrm{R}$; in this way, we made sure that the inferential results are not affected by critical individual differences but reflect the general behavior of all subjects.

No fixed effect in which Position was implied was found to be significant, but significant effects for Definiteness and Restrictiveness, as well as for the paired interaction Definiteness $\times$ Restrictiveness, were found. The main effect of Definiteness, $\chi^{2}(1)=68.15^{2}, p<.001$, suggests that monodefinite structures were better evaluated than polydefinite structures overall (Cohen's $d=1.36, p$ $<.001$ ). The main effect of Restrictiveness, $\chi^{2}(1)=9.951, p=.002$, suggests that restrictive contexts were better evaluated than non-restrictive contexts overall $(d=0.40, p=.002)$.

The paired interaction Definiteness $\times$ Restrictiveness, $\chi^{2}(1)=34.135, p<.001$, can be interpreted as such that polydefinites were better evaluated in restrictive contexts than in non-restrictive ones $(d=1.08, p<.001)$, whereas restrictiveness did not play a significant role when using monodefinite structures $(d=0.27, p$ $=.117$ ). The other way to interpret this finding would indicate a preference for monodefinite structures for both restrictiveness levels, though this preference would be larger for non-restrictive contexts $(d=2.03, p<.001)$ than for restrictive ones $(d=0.68, p=.001){ }^{7}$

\subsection{Discussion}

The results of the experimental study we conducted are in accordance with the biggest part of the polydefiniteness literature. Regarding the main effect of Definiteness, a general preference for monodefinite DPs over polydefinites was found. This could be an indirect reflex of the colloquial status of the latter (Manolessou 200o). Alternatively, it could be the result of the use of polydefinite DPs in the context of what- and who-questions, that-according to the Polydefiniteness constraint (Kolliakou 2004) - are predicted to be a bad host for this type of DPs. Crucially, the complementary analyses we ran failed to provide support to this latter claim: the specific $w h$-word had a significant influence on subjects' interpretations both in restrictively modified answers, $\chi^{2}(1)$ $=27.661, p<.001$, and in non-restrictively modified answers, $\chi^{2}(1)=12.673, p<$ .ool. Among the former, responses to what-questions were more accepted than responses to which-questions $(d=0.30, p<.001)$. Among the latter, responses to

7 Complementary item analyses for adjectives and $w h$-words are included in the Appendix. 
what-questions were more accepted than responses to who-questions $(d=0.19$, $p<.001$ ) (see the Appendix for details). As for the syntactic position of the DP, this, as expected, was not found to interact significantly with the acceptability of polydefiniteness.

Concerning our working hypothesis in (17), the link between polydefiniteness and restrictive modification was empirically confirmed (pace Alexiadou \& Wilder 1998; Campos \& Stavrou 2004; Kolliakou 2004; Lekakou \& Szendrői 2007, 2012; Alexiadou 2014). This finding suggests that any grammatical analysis of Greek polydefinite DP s should be able to derive the restrictive interpretation of the articled modifiers. However, before we move on, a comment on nonrestrictively modified polydefinites is due.

As the results in Figure 1 show, polydefinite DP s containing non-restrictive modifiers received ratings significantly lower than the restrictively modified ones, but still $>30 \%$ of acceptance. There are two ways to interpret this finding. The first one is to attribute the non-zero ratings to the fact that participants look for the interpretability of the phrases they are asked to judge; speakers do not consider non-restrictively modified polydefinites as grammatical but they can still ascribe an interpretation to them and, thus, mark them as borderline acceptable. Such a line of reasoning is backed by psycholinguistic studies that have found that ungrammatical constructions can be assigned systematic interpretations (Beltrama \& Xiang 2016; Wellwood et al. 2018; Etxeberria et al. 2018, among others) or can be easily learned (Kaschak \& Glenberg 2004; Ivanova et al. 2012, among others).

The other way would be to take the non-restrictively modified DP ratings to be revealing as to how direct the relationship between restrictiveness and polydefiniteness is. The idea is that the restrictive interpretation of the adjectives concerns only a part, although major, of polydefinite DPs, and that the Grammar of Greek can also generate non-restrictively modified polydefinites. Given that the mean acceptance rate of the latter was higher than $30 \%$, we consider the second alternative worth investigating and in need of an analysis. ${ }^{8}$

8 An anonymous reviewer suggests a third alternative to interpreting the obtained difference between restrictively and non-restrictively modified polydefinites: the restrictiveness constraint is interpretative, not grammatical, and no categorical judgments are, thus, expected. This is why polydefinites including non-restrictive adjectives are generally rated as of low but not zero acceptability.

The reason we do not adopt this alternative is because the findings we obtained under our what-, which- and who-question design suggest that the (non-)restrictiveness of a modifier is at least in part lexically constrained. This claim is corroborated by the item analysis included in the Appendix. On making the claim that restrictively modified polydefinites differ grammatically from their non-restrictively modified counterparts, we mean that the two series of adjectives receive separate representations in the grammar of native Greek speakers. 
In the next section, our interpretation of the results of the experiment is fleshed out as a novel formal analysis of polydefiniteness in terms of (non-)restrictive reduced relative clause modification. As is made clear in what follows, we derivationally dissociate the postnominal adjectives of Greek polydefinite DPs from the prenominal adjectives of monodefinites, for which we adopt standard assumptions (see Alexiadou et al. 2007 for an overview).

In the Introduction, Greek polydefinites were presented as displaying the following four characteristic properties: (i) they have colloquial status; (ii) they contain non-referring or referentially dependent definite determiners; (iii) they are interpreted as subject to Heim's (1982) Prominence Condition; and (iv) they are tightly related to restrictive modification. It is reminded that (iv) corresponds to our hypothesis (17), which was tested experimentally.

In light of the results of the experiment presented in Section 3, and pace Manolessou (2000) and Panagiotidis and Marinis (2011), we propose a modification of $(17)$, as given in $(21)$.

(21) There is a strong association between Greek polydefinite DP s and restrictive modification. However, polydefiniteness may also arise in nonrestrictively modified DPs.

The aim of the present section is to provide a syntactic analysis of polydefinites that accounts for the total of the data, critically building on the most influential formal proposals previously made within the generative framework.

Before we address that topic in the next section, it should be pointed out that the generative analyses of polydefiniteness can be coarsely categorized as follows: a) those that postulate a bi-DP flat structure for Greek polydefinites (Lekakou \& Szendrői 2007, 2012; Velegrakis 2011), ${ }^{9}$ b) those that treat them as involving a predication relation (Campos \& Stavrou 2004; Ioannidou \& den Dikken 2006; Panagiotidis \& Marinis 2011; Guardiano \& Stavrou 2019), and c) those that propose a restrictive relative clause substructure for this type of definite DPs (Alexiadou \& Wilder 1998; Cinque 2010; Alexiadou 2014; Giusti 2015). Let us look closely into each one of these categories.

9 Pereltsvaig (2007) provides an analysis in this spirit for double nominative constructions in Russian. 


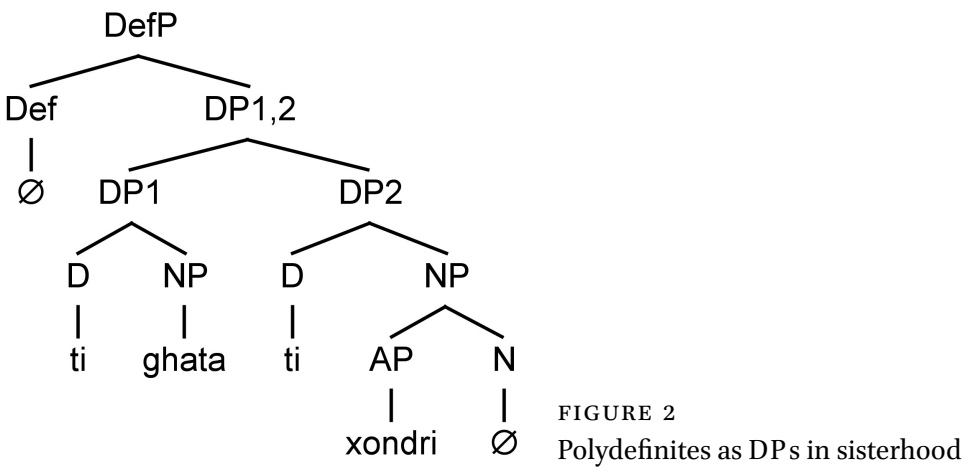

\subsection{Greek polydefinites: sister DPs and nominal ellipsis}

A notable example of structural economy is the analysis of polydefiniteness put forth by Lekakou and Szendröi $(2007,2012)$. The authors claim that Greek polydefinites should be regarded as close appositions involving nominal ellipsis. They start from the fact that polydefinite DPs display free ordering of constituents (see Section 2.1). Their proposal can be summarized as follows: two DPs - a full one and an elliptical one - enter a sisterhood relation and project a higher DP via referential role identification. This latter process is semantically translated into set intersection (Higginbotham 1985) and, Lekakou and Szendrői postulate, comes with the requirement that the two sets denoted by the two initial DPs be different from the one denoted by the resulting DP. If the two sister DPs must intersect to create a new, different set, then it follows that one of them, in the authors' system the elliptical one, is necessarily interpreted as restrictively modifying the other.

Crucially, Lekakou and Szendrői suggest that the upper layer of a nominal expression may contain a morphosyntactically active but semantically inert part - the DP where the definite determiner is merged - and a morphosyntactically null but semantically active part, namely Definiteness Phrase, to which the semantics of definiteness is attributed.

Figure 2 schematically represents the derivation of the polydefinite DP $t i$ ghata ti xondri (lit. the cat the fat 'the fat cat'), in the spirit of Lekakou and Szendrői (2012).

Such a proposal is structurally simple and gets the different constituent orders of polydefinites for free: the sister DPs can be merged in any order and no movements need to be postulated in one case or another. Furthermore, it predicts that the multiple determiners within a polydefinite DP do not independently pick discourse referents, as they are all expletive. The reference of the whole polydefinite is fixed by the single DefP. Finally, it derives the restrictive reading of the adjective by loading the process of referential role identi- 
fication, the mechanism that derives polydefiniteness, with the precondition that one of the referentially identified DPs must restrict the denotation of the other.

It is exactly this last advantage of Lekakou and Szendröi's proposal that causes its insufficiency. Under the referential role identification analysis, the restrictive reading of the adjective emerges as a prediction concerning all instances of Greek polydefiniteness. This means that the authors cannot account for non-restrictively modified polydefinites since, in such cases, the identification process would not apply; the two sister DPs, if intersecting at all, would derive a set identical to one of the initial sets.

Under closer inspection, the very introduction of nominal ellipsis in the analysis is problematic. The reason is that the part that is supposed to be elided can never be realized. Note the contrast between (22a) and (22b).

(22) a. ti ghata ti xondri

the cat the fat

'the fat cat'

b. *ti ghata ti xondri ghata

the cat the fat cat

If polydefinites involved nominal ellipsis, (22b) would be marginal but not ungrammatical (Giannakidou \& Stavrou 1999). Lekakou and Szendrói (2012) rule out such examples by resorting again to the postulation that referential role identification can apply only if the output set is different from both the input sets. In (22b) it crashes because the resulting set would be identical to the one denoted by the second DP ti xondri ghata. Notice though that, in this case, a stipulation is used to save another stipulation, namely the existence of nominal ellipsis in polydefinites. This turns out to be a conceptually weak point of the analysis.

Given the shortcomings identified right above, and in lack of more compelling evidence in support of analyzing polydefiniteness as a bi-DP structure, we provisionally abandon this first family of analyses.

\subsection{Polydefinites as Small Clause constructions}

The accounts that are included in this second group postulate a Small Clause (den Dikken 2006) substructure for Greek polydefinite DPs. Campos and Stavrou (2004), building on Demonte (1999) and Eide and Afarli (1999), provide one of the first analyses in this spirit. Returning to the fat cat example for expository purposes, they would argue that ti ghata ti xondri is a DP embed- 


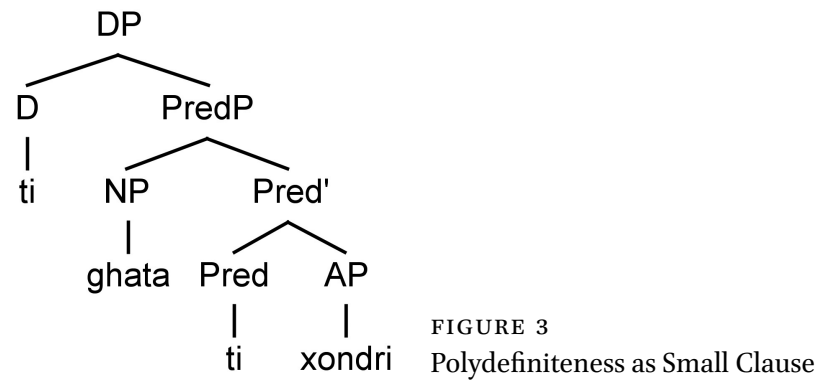

ding a predication by which the property of being fat is predicated of the cat. According to them, only the first article is a definite determiner; the preadjectival article is merely the instantiation of the predicative head in a nominal environment, with a definiteness feature obtained from $\mathrm{D}$ via concord, known to be extensive within the Greek DP. Figure 3 shows a simplified version of their proposal. ${ }^{10}$

As illustrated above, Campos and Stavrou commit to the order DET+NOUN+ DET+ADJ being the basic one for polydefinites. They derive the opposite order via focus movement of Pred' to Spec,DP, which has been independently argued to host focused constituents in Greek (Horrocks \& Stavrou 1987).

Campos and Stavrou's (2004) analysis can derive the different constituent orders that polydefinite DPs display. What is more, if the doubled article that emerges in polydefinite environments is a predicative head, the fact that only one article-in their view the prenominal one-fixes the reference of the whole DP is captured. The authors derive the strong relationship of the phenomenon to restrictive modification indirectly. They consider polydefiniteness as the Greek equivalent of postnominal modification in Romance languages (see also Alexiadou et al. 2007; Guardiano \& Stavrou 2019). Since postnominal adjectives in these languages are most usually interpreted restrictively (Bouchard 2002), a connection between polydefinites and restrictive modifiers is predicted. Lastly, it should be mentioned that Campos and Stavrou draw a parallel between polydefiniteness and clitic doubling in the verbal domain, since the two constructions display formal and interpretational similarities: Like polydefinites, clitic doubled DPs are subject to Heim's Prominence Condition (Anagnostopoulou 1994). However, they do not provide any syntactic reflex of this parallel (Alexiadou 2014).

The Small Clause analysis of polydefiniteness described above has been criticized for not being able to rule out non-restrictively modified polydefinites

10 The simplified version of the structure is taken from Guardiano and Stavrou (2019: 37). See also Campos and Stavrou (2011, 2012). 
(Alexiadou 2014). Even though Campos and Stavrou relate the phenomenon to restrictive modification, there is nothing in their structure that makes this association a grammatical constraint. However, in light of the results presented in Section 3 and our revised hypothesis (21), this could be considered an asset. Leaving this aside, and abstracting away from the technicalities of the account, we find two reasons to refrain from a Small Clause analysis of polydefiniteness along these lines.

The first reason is a theoretical one. The idea that the Greek vocabulary item usually regarded as the definite article might instantiate two distinct categories - a definite determiner and a predicative head — raises doubts stemming from their status in grammar. Although legitimate, the proliferation of the lexicon is undesirable if more economical alternatives are available.

The second reason is empirical. Observe the following minimal pair.

(23) a. Pini to nero krio.

drinks the water cold

'She drinks the water cold.'

b. Pini to nero to krio.

drinks the water the cold

'She drinks the cold water.'

Example (23a) involves a prototypical small clause (the water cold) and can be paraphrased as 'She drinks the water while/when it's cold'. Notice that there is no overt element lexicalizing the predicative head of this small clause, but the sentence is grammatical. Now, if a second article is introduced, $(23 \mathrm{~b})$ is generated; the small clause is substituted for a polydefinite DP and the whileinterpretation is no longer available. The right paraphrase for $(23 b)$ is 'She drinks the water which is cold'.

Although it is not theoretically necessary that all small clauses have identical structure, the pair in (23) seems to provide evidence that the predicative head in nominal small clauses in Greek can be null. Notice also that the structure proposed by Campos and Stavrou for polydefinites seems a great fitting for (23a). Keeping the notation to the minimum, the latter can be structurally represented as in (24).

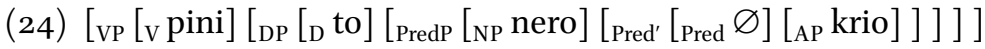



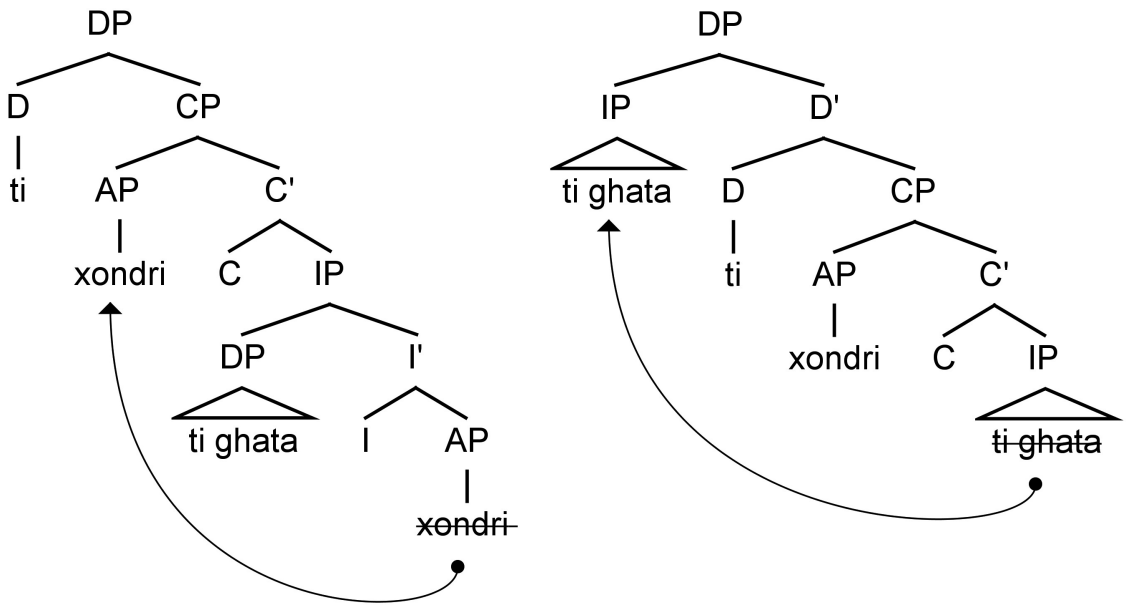

FIGURE 4 Polydefinites as reduced restrictive relatives

This probably means that the same analysis should not be applied to (23b) and that polydefinite DPs have a syntax more complex, or at least different from standard small clauses.

Bearing in mind the theoretical and empirical counterarguments to a Small Clause analysis of polydefiniteness presented above, we move on to the third alternative anticipated in the beginning of the section.

\subsection{Polydefinites as reduced relative clauses}

The last family of polydefiniteness analyses to be presented comprises those studies which postulate a restrictive relative clause structure for this type of definites. Alexiadou (2014) provides one of the most complete accounts of polydefinite DPs in this line. ${ }^{11}$ She adopts Kayne's analysis of relatives. Contra Campos and Stavrou (2004), she considers the order DET+ADJ+DET+NOUN as the unmarked one.

Modifying our example accordingly, Alexiadou's system would derive the polydefinite DP tixondritighata as follows: the first determiner takes a reduced (tenseless) relative $\mathrm{CP}$ as a complement. This relative embeds a predication structure via which the property denoted by $x$ ondri is predicated of the definite DP tighata. The surface constituent order arises through predicate fronting of xondri to Spec,CP. The derivation is illustrated schematically in Figure 4. The inverted constituent order, shown on the right, is obtained via movement of the embedded subject DP to the Specifier of the highest DP, presumably for focus reasons (Horrocks \& Stavrou 1987).

11 For a previous version of this analysis, see Alexiadou \& Wilder (1998). 

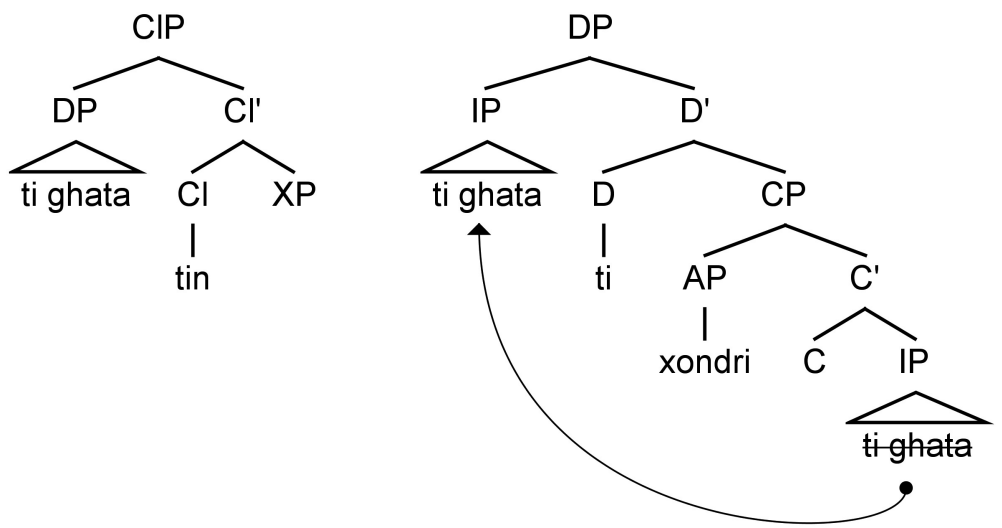

FIGURE 5 Clitic doubling (Anagnostopoulou 1994) and polydefiniteness (Alexiadou 2014)

Like the other two analyses previously presented, Alexiadou's (2014) proposal can account for the different constituent orderings found in Greek polydefinites. By resorting to a reduced restrictive relative clause substructure, she gets for free the restrictive reading of the adjectives found in polydefinite DPs. Interestingly, she claims that her analysis explains also the Prominence (Heim 1982) of polydefinites. In her view, the structure provided for inverted polydefinite examples is parallel to Anagnostopoulou's (1994) account of clitic doubling in the verbal domain, an oversimplified version of which is given in Figure 5. Alexiadou's inverted polydefinite is repeated for ease of comparison.

Starting from the restrictiveness issue, Alexiadou's analysis cannot be all there is to polydefiniteness; it does not account for the existence of nonrestrictively modified polydefinites, for which our experiment provides empirical support. The question to be addressed next is whether it is appropriate for the restrictively modified ones.

The idea to analyze polydefiniteness in a way parallel to clitic doubling is inspiring. However, the similarity between the two structures is not straightforward. Importantly, the parallel is drawn between the Clitic Phrase and the polydefinite DP to which focus fronting has applied. This is unexpected given that, according to Alexiadou (2014), this is the marked polydefinite variant. But even if this is ignored, the similarity between the two constructions turns out to be merely impressionistic: While in clitic doubling the doubled DP has an intrinsic relationship with the clitic and moves to its specifier to establish a Spec-Head relation, the definite subject DP of the polydefinite optionally moves to the specifier of the highest DP to be interpreted as focused. Apparently, the analysis does not satisfactorily establish the structural affinity between the two con- 
structions and, thus, cannot account for the Prominence constraint to which polydefinites are subject.

The main reason we believe Alexiadou's proposal cannot be adopted as it is, though, has to do with the fact that the meaning of the two definite determiners that appear in the structure in Figure 4 is not made precise. It appears that in her system it is the preadjectival determiner that is translated as the iota operator, while the prenominal one is referentially inert. Although counter-intuitive, especially for the cases of inverted polydefinites, this is indeed a possibility. What remains a problem is that, the way Alexiadou's structural analysis is formulated, it does not clearly suggest any dependency between the two definite determiners. This means that their identity of reference, which has been presented as one of the characteristic properties of polydefiniteness, is not guaranteed. It is probably the case that she has a way of making the embedded determiner referentially dependent or inactive, but this way remains unspecified.

In what follows, we introduce a novel structural analysis of polydefiniteness as involving restrictive or non-restrictive relative clause modification, that aspires to evading the shortcomings of its predecessors.

\subsection{Polydefinites as obligatorily resumed relative clauses}

Following the main insight of Alexiadou and Wilder (1998), later taken up by Cinque (2010), Alexiadou (2014) and Giusti (2015), we agree that polydefiniteness of the Greek type should be analyzed in terms of relative clause modification. However, instead of adopting an approach to polydefinite relatives inspired on Kayne (1994), a syntax of relatives similar in spirit to Jackendoff (1977) and Demirdache (1991) is adopted, partially implemented also in Giusti (2015).

The main intuition behind the link we postulate between Greek polydefinites and relative clauses can be described, pretheoretically, as the idea that the pairs in examples (25) and (26) below, involving restrictive and non-restrictive modification respectively, are semantically and syntactically parallel.

(25) a. ti ghata pu ine xondri

the cat COMP is fat

'the cat that is fat'

b. ti ghata ti xondri

the cat the fat

'the fat cat' 


\section{(26) a. tin atmosfera, pu ine ekpliktiki the atmosphere COMP is amazing 'the atmosphere, which is amazing'}

b. tin atmosfera tin ekpliktiki the atmosphere the amazing 'the amazing atmosphere'

While the similarity in meaning is obvious, the structural parallelism between the relative clause $(25 \mathrm{a}, 26 \mathrm{a})$ and the polydefinite DP $(25 \mathrm{~b}, 26 \mathrm{~b})$ seems a bit more far-fetched.

The reader may notice that both the restrictive and the non-restrictive relative clause are introduced by the overt complementizer $p u$ and apparently involve a null relative operator. ${ }^{12}$ On the contrary, neither a complementizer nor a relative operator is found in polydefinite DPs. What appears in the latter is a definite determiner preceding the adjectival predicate. How can this be related to a relative clause structure? Although in the examples above we gloss this determiner as a definite article, we argued in the previous sections that it seems to be neither that nor a predication head. A third alternative emerges after a little more digging into relative clauses.

Alexopoulou (2006) brings to attention restrictive (27) and non-restrictive (28) relative clauses in Greek to which resumption applies.

(27) $i_{i} \quad$ kiria pu tis $s_{i}$ zitises anaptira the lady COMP RESP asked-2SG lighter 'the woman whom you asked for a lighter'

(28) $i_{i}$ tenia, pu tin $_{i}$ idhame xthes the movie COMP RESP saw-1PL yesterday 'the movie, which we watched yesterday'

12 In the absence of $p u$, Greek relative clauses are introduced by an overt wh-operator.

(i) $i$ ghata $i$ opia ine xondri the cat the REL is fat 'the cat which is fat'

(ii) $i$ atmosfera, $i$ opia ine ekpliktiki the atmosphere the REL is amazing 'the atmosphere, which is amazing'

We omit this from our discussion here for simplicity, since it does not really affect how the parallel between relatives and polydefinite DP s should be pursued. 
The elements that are in bold are resumptive pronouns, which in Greek are morphologically identical to definite articles. We take exactly this to be the missing link between relative clauses and polydefinite DPs. If resumption emerges in full relatives, then it is only expected that it can also appear in the reduced relatives of the polydefiniteness kind. What is seemingly an additional definite article in the latter turns out to be a resumptive pronoun, that provides evidence for the embedding of a relative clause substructure. ${ }^{13}$

Alexopoulou (2006) gives a thorough analysis of how and why resumption emerges in full restrictive and non-restrictive relative clauses in Greek. Leaving aside the technical details, we adopt from her the main insights that (i) resumption can apply for purely formal reasons, namely successful agreement and, in minimalist terms, deletion of uninterpretable features and (ii) the presence or absence of resumption in relative clauses depends on the featural specification of the relative complementizer (see also Alexopoulou 2010). We claim that resumption applies in the relative clauses of the polydefinite type, based on similar considerations.

Specifically, our proposal can be described as follows: Greek polydefiniteness arises whenever a definite nominal is modified by a reduced restrictive or non-restrictive relative clause whose complementizer (C) head bears an unvalued definiteness [uDef] feature that triggers AGREE/MOVE. Such reduced relative clauses are introduced by a null $\mathrm{C}$ that, similarly to its overt counterpart $p u$ (Roussou 1994; Alexopoulou 2006), bears a definiteness feature, but differently from it lacks a $[\mathrm{uWh}]$ feature. In this analysis of polydefinites the [uDef] feature on C obligatorily triggers resumption — grammatical resumption in the terms of Alexopoulou (2010): a resumptive clitic pronoun with an [iDef] feature is merged in the subject position of the predication that is embedded under the relative $C$. AGREE between $C$ and the resumptive clitic values and checks the [uDef] feature on C. MOVE follows AG REE for the satisfaction of EPP and triggers movement of the resumptive pronoun to Spec,CP. This is how the derivation of a polydefinite DP becomes complete. Before we move on to see how concrete examples are derived in the way just described, two clarifications need to be made.

The first thing that we need to make explicit is that, in contrast with $p u$ that introduces standard relative clauses in Greek, we do not postulate any [uWh] feature on the null $\mathrm{C}$ that introduces the reduced relative of polydefinites, the

13 To our knowledge, Giusti (2015) is the first one to relate the doubled definite determiner of polydefinites to a relative pronoun. See also Franco et al. (2015), for the claim that the preadjectival article of what could be considered as polydefiniteness in Albanian has pronominal status. 


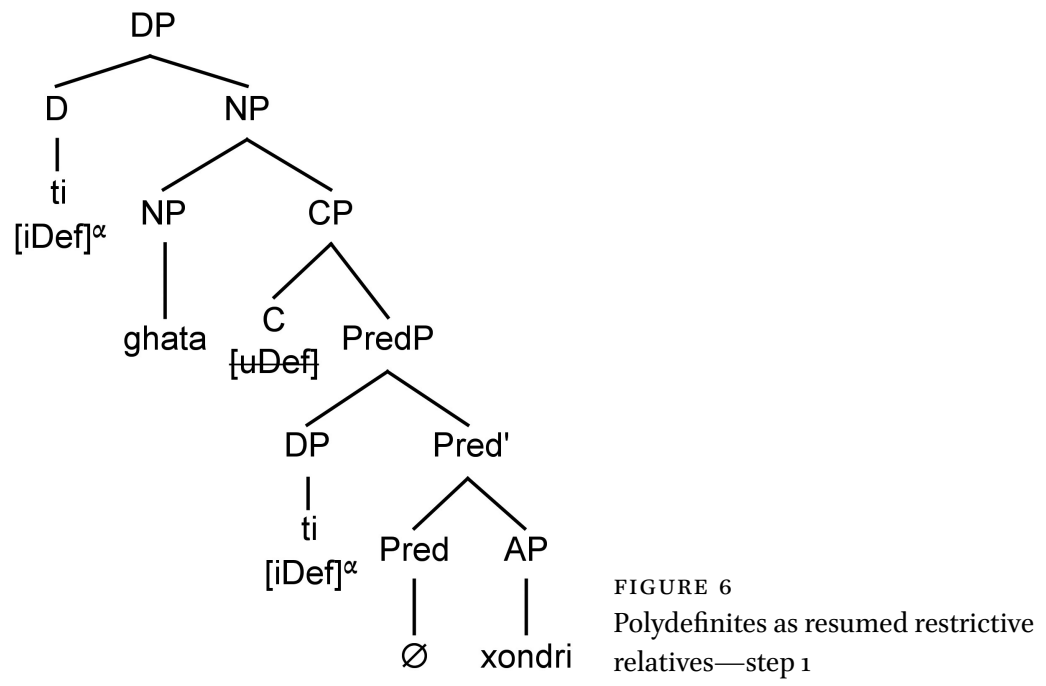

main reason being that no morphologically wh-element can ever appear in this construction. Notice that the role that $[\mathrm{uWh}]$ plays in full relatives is, in our case, taken up by [uDef]. Interestingly, definiteness has been independently argued to substitute for other features in order to allow a derivation to converge (Delfitto et al. 2009).

The second clarification due concerns the status of the resumptive clitic. Given the lack of consensus in the literature as to the exact nature of resumptive pronouns (see Rouveret 2011 for an overview), we follow the most economical alternative indicated by Doron (2011) and take resumptive clitics to be similar not to gaps, but to standard pronouns. This allows that, in our system, the resumptive element is not interpreted as a variable bound by a relative operator, which is absent from our structure. It predicts, instead, that the resumptive pronoun can be anaphorically bound by an antecedent.

We suggest that, in the case of Greek polydefinites, the antecedent that binds the resumptive pronoun is the topmost definite article, the determiner that emerges as the prenominal one. To formally represent this anaphoric relationship, we mark the [iDef] feature of the clitic as sharing a referential superscript with the [iDef] feature encoded in the highest definite article; this cosuperscription guarantees the identity of reference of the two elements, which has been presented as one of the characteristic properties of polydefiniteness.

With all these details in place, we can now move on to the examples. Let us start with restrictive reduced relative clauses and the polydefinite DP tighata ti xondri from example (25b). Figure 6 schematically represents the first step of the derivation. Only the features relevant for our purposes are specified. 


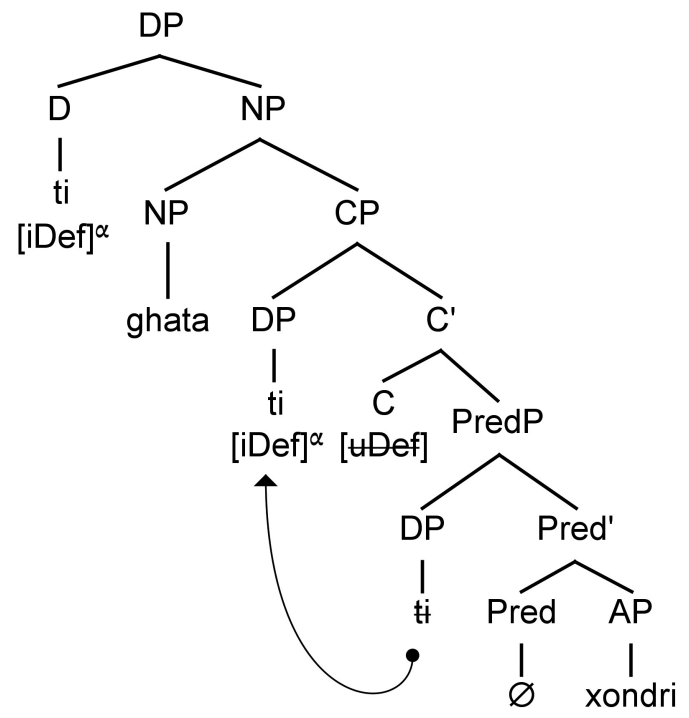

FIGURE 7

Polydefinites as resumed restrictive relatives-step 2

As anticipated, a resumptive pronoun realizing the subject of the embedded predication is merged in Spec,PredP. C enters an AGREE relation with the pronoun to value and check its [uDef] feature. MOVE is parasitic on AGREE and it is motivated by the requirement that the Spec,CP must be filled (EPP). As a result the resumptive pronoun moves to Spec,CP. This is the second and last step of the derivation of the polydefinite DP, displayed in Figure 7.

There is a parallel here with full relatives: By standard assumptions, in the full case, it is a $[\mathrm{uWh}]$ feature on $\mathrm{C}$ that triggers AGREE and MOVE of an [iWh] element to Spec,CP; in a parallel fashion, in the reduced relatives of the polydefiniteness kind, the same derivational procedure takes place, triggered by a [uDef] feature and attracting an [iDef] pronoun.

Concerning the interpretation of the resumptive clitic, co-superscription with the c-commanding topmost determiner on D shows that reference is made to a unique individual identifed from the context (or discourse) that has the intersective properties of being a cat and being fat. In other words, the preadjectival resumptive pronoun is referentially bound to the prenominal definite article. This is how the obligatory co-reference of the two determiners, which was presented as one of the characteristic properties of Greek polydefiniteness, arises.

As for the inverted polydefinite, we follow the insight of Campos and Stavrou (2004) and postulate movement of the whole CP to the specifier of the highest DP, for focus reasons. The derivation of the polydefinite tixondri tighata is represented in Figure 8. In this configuration the feature [iDef $]^{\alpha}$ in prenominal 


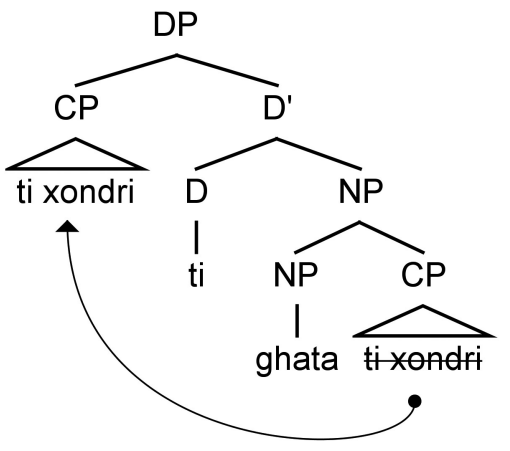

FIGURE 8

Inverted polydefinites

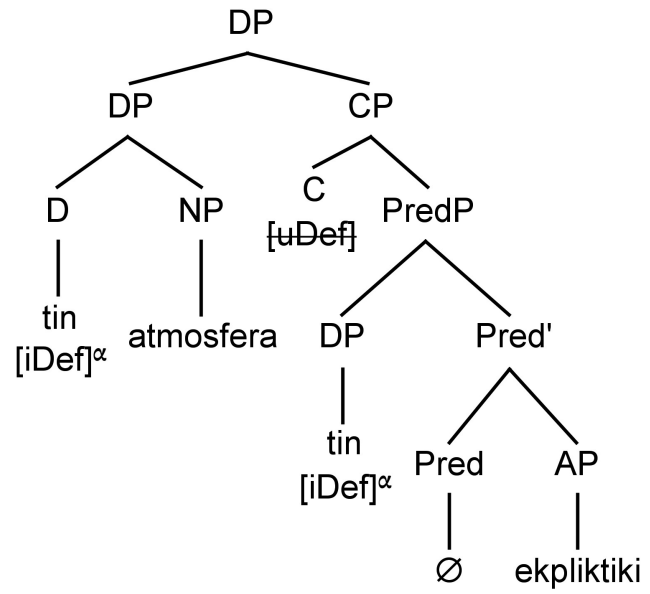

FIGURE 9

Polydefinites as resumed non-

restrictive relatives - step 1

position still c-commands the feature $[\mathrm{iDef}]^{\alpha}$ of the embedded clitic pronoun, thus guaranteeing their identity of reference.

It is now time to move on to polydefinite DPs involving non-restrictively interpreted adjectives. We suggest that they are derived in the same way as polydefinites containing restrictive modifiers, modulo the fact that in this latter case the reduced relative clause, being non-restrictive, adjoins to DP instead of NP. This idea is found under different terms in Jackendoff (1977), and it is explicitly stated in Demirdache (1991). Let us take the polydefinite DP tin atmosfera tin ekpliktiki from (26b) as our example. In Figure 9 the first step of the derivation is shown.

As in restrictive reduced relatives, MOVE follows AGREE for the satisfaction of $\mathrm{EP}$, and the resumptive pronoun merged in Spec,PredP is moved to Spec,CP. The output of this movement, that is the final step in the derivation of the nonrestrictively modified polydefinite, is displayed in Figure 10. 


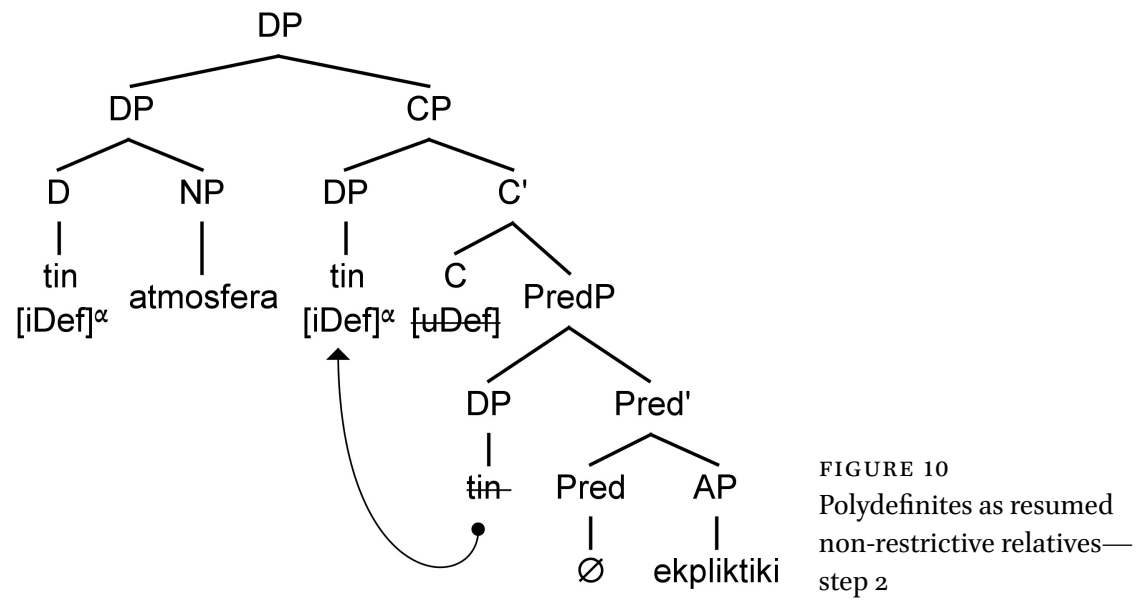

A possible objection at this point is that in Figure 10 the definite article merged in the highest $\mathrm{D}$ position does not straightforwardly c-command the resumptive clitic, putting the co-superscription of the two at risk. Our answer to this problem is that, since there is adjunction, the referential index introduced by the definite article and encoded as the [iDef $]^{\alpha}$ feature percolates by principle to the maximal DP projection, thus guaranteeing that the prenominal determiner binds the resumptive clitic. It is exactly this climbing of the referential index that allows the postulated referential dependency also when there is inversion. Notice that in the case of the polydefinite tin ekpliktiki tin atmosfera no movement needs to be postulated, since the reduced relative is a DP-adjunct. ${ }^{14}$

The analysis of Greek polydefiniteness as involving reduced restrictive or non-restrictive relative clauses presented in this section achieves the desired empirical adequacy: It derives both the basic and the inverted constituent order of polydefinite DPs, at the same time predicting modification by restrictive and non-restrictive modifiers. By treating the doubled article as a resump-

14 A reviewer suggests that the presence of a demonstrative imposes restrictions on the constituent order of a non-restrictively modified polydefinite:

(i) afti $i$ parastasi $i$ katapliktiki

this the show the amazing

'this amazing show'

(ii) \#afti $i$ katapliktiki $i$ parastasi

this the amazing the show

'this amazing show'

We make no claim regarding this potential asymmetry since this kind of complex polydefinites did not form part of our experimental study. 
tive pronoun, it explains why it cannot independently introduce discourse referents but is referentially dependent on the highest, prenominal determiner. ${ }^{15}$

Our analysis has a theoretical advantage as well: the syntactic and semantic mechanisms it resorts to to derive polydefiniteness are also found in other constructions in Greek and other natural languages. Specifically, resumptionwhich was claimed to be the reason for the apparent spreading of the definite determiner-emerges in full relatives in Greek. Therefore, it is not surprising that, under analogous syntactic conditions, it appears in reduced relative clauses too. Moreover, the postulated referential dependency between the two definite determiners, which predicts that it is always the prenominal definite article that fixes the reference of the whole polydefinite DP while the resumptive clitic is interpreted as a bound anaphor, has been also argued to hold for the so-called long weak definites in various languages (Poesio 1994; Barker 1998; Espinal \& Cyrino 2017, among others).

The next question to be addressed is the following: Does our analysis have anything to say about the Prominent (Heim 1982) interpretation of polydefinites (Tsakali 2008; Alexiadou 2014)? At first sight, the answer seems to be negative: The account of polydefiniteness proposed here does not resemble Anagnostopoulou's (1994) analysis of clitic doubling in any substantial way. This would mean that, like the previous analyses of Greek polydefinites, this one also fails to fully capture their interpretation.

Under closer inspection though, it turns out that our account does make a prediction about the discourse status of the entities to which a polydefinite DP refers. Recall that we have treated the preadjectival article of polydefinites as a resumptive pronoun that emerges within a relative clause configuration. A parallelism between resumption in relative clauses and clitic left dislocation

15 A reviewer observes that our analysis predicts resumption also in nominative case, which is never found in full relatives in Greek. According to Alexopoulou (20o6), resumption applies in full restrictive relative clauses whenever the $\varphi$-features of the trace of the relativized head are not otherwise recoverable. Resumption never happens with nominative traces, since, in Greek, the $\varphi$-features of a subject are always visible on the verb. Regarding non-restrictive relatives, resumption is obligatory with any kind of argument, because the relative operator needs to bind a coreferential clitic at LF (Alexopoulou 2006). Nominative resumption is again excluded and it appears that, in the case of subjects, the derivation converges with the relative operator binding a null pro. The generalization that can be drawn is that resumption applies in full relative clauses to make $\varphi$-features visible and satisfy requirements at the level of syntax or interpretation. On the other hand, we argue that, in the case of polydefinites, the trigger of resumption is the satisfaction of a [uDef] feature on the null $\mathrm{C}$ introducing the reduced relative clause. Since the relevant feature in this case is definiteness and not $\varphi$-features, the syntactic role of the pronominal does not play a role and nominative resumption is not excluded. 

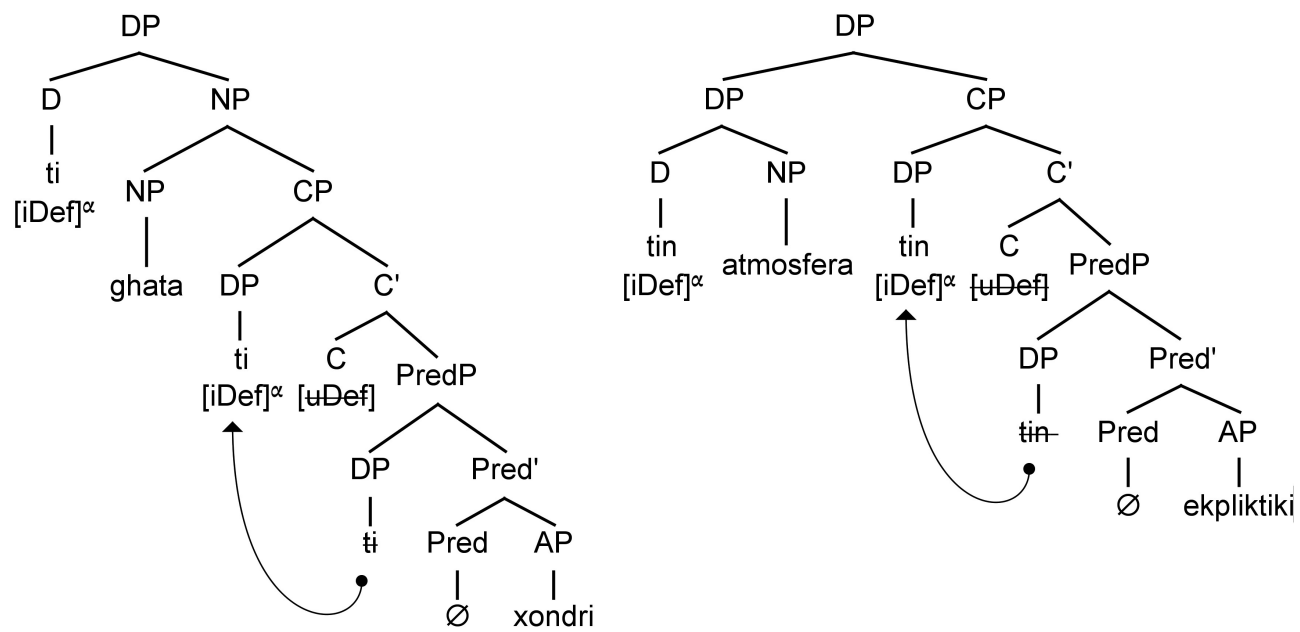

FIGURE 11 Polydefinites as resumed reduced relatives

constructions is hinted at already in Anagnostopoulou (1994) $\cdot{ }^{16}$ We make use of this parallelism to defend that Greek polydefinites are interpreted as d-linked expressions (Pesetsky 1987).

In Figure 11 we repeat the proposed derivation for a restrictively and a nonrestrictively modified polydefinite. The two structures share the existence of a base-generated definite determiner that is translated as an iota operator and referentially binds a resumptive pronoun in argument position of a lower predication. Given that this is the essence of clitic left dislocation and that clitic left dislocated DPs are by standard assumptions d-linked (Anagnostopoulou 1994), we claim that our analysis of polydefiniteness predicts that polydefinite DPs are also interpreted as d-linked.

The above claim seems to make an undesirable prediction. Given that specific indefinites can also be clitic left dislocated, one could argue that our analysis generates indefinite polydefinites ${ }^{17}$ of the type displayed in (29), which are ungrammatical.

(29) * mia ghata ti xondri

a cat the fat

'a fat cat' (intended interpretation)

16 A similarity between clitic left dislocation and non-restrictive relatives is also stressed in Tsimpli (1995) and Alexopoulou (2006), among others.

17 The term is used here merely as a label, for expository purposes. 
Remember however that, in our account, the referential binding relationship between the prenominal definite article and the preadjectival resumptive clitic is established via sharing of an identically superscripted definiteness feature [iDef $]^{\alpha}$. Such a feature is absent from (29) since mia ghata is indefinite; no binding can take place and the derivation crashes. Therefore, only the modification of definite nominals by reduced relative clauses leads to polydefiniteness. ${ }^{18}$

Given the above, our proposal can be summarized as follows: Greek polydefiniteness is the nominal counterpart of clitic left dislocation in the sentential domain. It involves morphologically definite DPs that are interpreted as dlinked expressions. This last claim is admittedly weaker than Tsakali's thesis that polydefinites are subject to Heim's (1982) Prominence Condition. On the other hand, it fits perfectly the Polydefiniteness constraint (see Section 2.3); our analysis provides a syntactic reflex of the (non-monotone) anaphoric discourse function of polydefinites, introduced in Kolliakou (2004). ${ }^{19}$

Assuming that our line of thinking described in this last section is on the right track, there is still a comment pending. Our analysis predicts both restrictively and non-restrictively modified polydefinite DPs. What it does not predict is that the former are significantly preferred over the latter, as our experimental study showed. This is indeed a liability calling for further research.

Before we conclude, a clarification needs to be made. It has been argued here that polydefiniteness is a case of postnominal modification, by either restrictive or non-restrictive modifiers. This might sound strange, or at least parochial,

18 An alternative not pursued in this paper for simplicity is that the [iDef] feature in our structures can be either positively or negatively valued. In the first case, a polydefinite emerges. In the second, the topmost $\mathrm{D}$ agrees with the resumptive clitic in indefiniteness. Indefinite clitics in Greek are null (Panagiotidis 2002). This is how our system would derive polyindefinites (Alexiadou 2014).

(i) mia ghata xondri

a cat fat

19 Kolliakou argues that Greek polydefinite DPs are non-monotone anaphoric expressions. In formulating her Polydefiniteness constraint, she makes this claim more specific, by adding the prediction that the articled adjectives of polydefinites are interpreted restrictively. Interestingly, though, she also claims the following: "According to the [Non-Monotone Anaphora Hypothesis], $\mathrm{X}$ (the antecedent set) should not be a subset of or equal to $\mathrm{Y}$ (the set corresponding to the link). This formulation allows for two cases: either (a) the previously introduced set is larger (i.e. the set $Y$ that the link picks out is a proper subset of the antecedent set X), or (b) the two sets do not intersect" (Kolliakou 2004: 272). We take non-restrictively modified polydefinite DPs, for the existence of which our experimental study provided evidence, as instantiating case (b).

See Kolliakou (2004), also on the parallel between Greek polydefinites and English deaccented nominals. 
given that postnominal adjectives are most usually related to restrictive modification, at least in languages that allow for both prenominal and postnominal modifiers (see Alexiadou et al. 2007 and references therein). As has been suggested throughout, we derivationally dissociate the adjectives of polydefinite DPs from those found in monodefinites. Adopting standard assumptions for the latter (see Alexiadou et al. 2007 for an overview), we claim that polydefiniteness is different; it is a subcase of relative clause modification. Thus, it can involve modifiers interpreted restrictively or non-restrictively.

\section{5}

\section{Conclusions}

This study has contributed to the literature on Greek polydefiniteness by providing linguistic evidence related to a specific aspect of the phenomenon: the obligatoriness of the restrictive interpretation of the articled adjectives in polydefinite DPs. In accordance with most of the previous studies on the topic (Kolliakou 1995, 2004; Alexiadou \& Wilder 1998; Campos \& Stavrou 2004; Lekakou \& Szendrői 2012; Alexiadou 2014; Guardiano \& Stavrou 2019, among others), our experimental study has confirmed that Greek speakers have a strong preference for restrictively modified polydefinites over non-restrictively modified ones. However, it has also suggested that the latter are dispreferred but not excluded by grammar (pace Manolessou 2000; Panagiotidis \& Marinis 2011).

To accommodate the finding above, we have proposed a novel syntactic analysis of Greek polydefinites. Building on the main insight in Alexiadou and Wilder (1998), Alexiadou (2014) and Giusti (2015), we have related polydefiniteness to relative clauses, substantially departing from previous accounts in suggesting that polydefinite DPs be analyzed as definite DPs modified by either restrictive or non-restrictive reduced relatives.

Extending Alexopoulou's (2006) analysis of resumption in full Greek relative clauses, we have claimed that resumption applies also in reduced relatives of the polydefiniteness type, triggered by the need of the embedded relative complementizer to value its unvalued definiteness feature. Under such an account, what has been previously considered as an additional determiner (Lekakou \& Szendrői 2012; Alexiadou 2014) or a predicative head in polydefinite DPs (Campos \& Stavrou 2004) is analyzed as a resumptive pronoun.

Our analysis predicts the existence of both restrictively and non-restrictively modified polydefinites, the difference between them being that, while the former are generated via modification by reduced restrictive relative clauses, the latter are derived via modification by reduced non-restrictive relative clauses. 
Crucially, both types of reduced relatives mirror their respective full counterparts syntactically and semantically.

Our analysis is also consistent with other properties previously ascribed to polydefinite DPs. By deriving a referential dependency between the multiple determiners that appear within the same phrase, it accounts for their obligatory identity of reference and draws a parallel between Greek polydefinites and long weak definites found in several languages. By introducing resumption in the analysis, it brings polydefiniteness close to clitic left dislocation in the sentential domain, thus anticipating that, as do clitic left dislocated DPs, polydefinite DPs are interpreted as d-linked expressions.

\section{Supplementary materials}

For reasons of space, supplementary material providing the raw data used in this study is included as an Appendix. This was submitted by the authors with the original manuscript. The supplementary materials can be found here: https://doi.org/10.6o84/mg.figshare.14706303.

\section{Acknowledgements}

We would like to thank two anonymous reviewers and the editors of the Journal of Greek Linguistics for their invaluable comments. We would further like to thank the audience of the Linguistic Evidence 2020 conference hosted by the University of Tübingen, where a previous version of this study was presented. All errors in this paper remain our own. The present research acknowledges funding from Spanish M INE CO (FFI2017-82547-P) and the Generalitat de Catalunya (2017SGR634) and an ICREA Academia awarded to the last author.

\section{References}

Alexiadou, Artemis. 2014. Multiple determiners and the structure of DPs. Amsterdam: John Benjamins. doi.org/10.1075/la.211

Alexiadou, Artemis, Liliane Haegeman \& Melita Stavrou. 2007. The noun phrase in the Generative perspective. Berlin: De Gruyter. doi.org/10.1515/9783110207491

Alexiadou, Artemis \& Chris Wilder. 1998. Adjectival modification and multiple determiners. In Possessors, predicates and movement in the DP, ed. by Artemis Alexiadou \& Chris Wilder, 303-332. Amsterdam: John Benjamins. doi.org/10.1075/la.22.11ale 
Alexopoulou, Theodora. 2006. Resumption in relative clauses. Natural Language \& Linguistic Theory 24: 57-111. doi.org/10.1007/s11049-005-0898-2

Alexopoulou, Theodora. 2010. Truly intrusive: Resumptive pronominals in questions and relative clauses. Lingua 120: 485-505.

Anagnostopoulou, Elena. 1994. Clitic dependencies in Modern Greek. Doctoral dissertation, University of Salzburg, Austria.

Androutsopoulou, Antonia. 1995. The licensing of adjectival modification. Proceedings of the fourteenth West Coast Conference of Formal Linguistics, ed. by Jose Camacho, Lina Choueiri \& Maki Watanabe, 17-31. Stanford, CA: CSLI Publications.

Barker, Chris. 1998. Partitives, double genitives and anti-uniqueness. Natural Language \& Linguistic Theory 16(4): 679-717.

Beltrama, Andrea \& Ming Xiang. 2016. Unacceptable but comprehensible: The facilitation effect of resumptive pronouns. Glossa: A Journal of General Linguistics 1(1): 29.1-24. doi.org/10.5334/gjgl.24

Bouchard, Denis. 2002. Sériation des adjectives dans le SN et formation de concepts. Recherches linguistiques de Vincennes 34.125-142.

Campos, Hector \& Melita Stavrou. 2004. Polydefinites in Greek and Aromanian. Balkan syntax and semantics, ed. by Olga Tomic, 137-173. Amsterdam: John Benjamins.

Campos, Hector \& Melita Stavrou. 2011. Definiteness effects in Spanish and Greek (appositive) nominals. Paper presented at Colloquium on Generative Grammar (CGG), Sevilla, April 7-9, 2011.

Campos, Hector \& Melita Stavrou. 2012. Emotional appositives in Spanish, Greek and Balkan Romance. Presentation at the Workshop on Balkan-Romance Linguistics. Università Ca' Foscari, Venice, March 13, 2012.

Cinque, Guglielmo. 2010. The syntax of adjectives. A comparative study. Cambridge, MA: MIT Press.

Delfitto, Denis, Chiara Melloni \& Ur Shlonsky. 2009. Licensing arguments within nounphrases: On the nature of genitive case. La grammatica tra storia e teoria. Scritti in onore di Giorgio Graffi, ed. by Paola Cotticelli-Kurras \& Alessandra Tomaselli, 67-92. Alessandria: Edizioni dell'Orso.

Demirdache, Hamida. 1991. Resumptive chains in restrictive relatives, appositives and dislocation structures. Doctoral Dissertation, MIT.

Demonte, Violeta. 1999. El adjetivo: clases y usos. La posicion de l'adjetivo en el sintagma nominal. Gramatica descriptiva de la lengua española, ed. by Ignacio Bosque \& Violeta Demonte, 129-215. Madrid: Espasa-Calpe.

den Dikken, Marcel. 20o6. Relators and linkers: The syntax of predication, predicate inversion, and copulas. Cambridge, MA: MIT Press.

Doron, Edit. 2011. On the syntax and semantics of resumptive pronouns. Resumptive pronouns at the interfaces, ed. by Alain Rouveret, 289-318. Amsterdam: John Benjamins. 
Eide, M. Kristin \& Tor A. Afarli. 1999. The syntactic disguises of the predication operator. Studia Linguistica 53: 155-181.

Espinal, M.Teresa. (to appear). Expletive pronouns and expletive articles. The Oxford handbook of determiners, ed. by Solveiga Armoskaite \& Martina Wiltschko. Oxford: Oxford University Press.

Espinal, M.Teresa \& Sonia Cyrino. 2017. The definite article in Romance expletives and long weak definites. Glossa: A Journal of General Linguistics 2(1): 23.1-26. doi.org/10 $.5334 /$ gjgl.16o

Etxeberria, Urtzi, Susagna Tubau, Viviane Déprez, Joan Borràs-Comes \& M.Teresa Espinal. 2018. Relating (un)acceptability to interpretation. Experimental investigations on negation. Frontiers in Psychology 8.2370. doi.org/10.3389/fpsyg.2017.02370

Franco, Ludovico, M. Rita Manzini \& Leonardo M. Savoia. 2015. Linkers and agreement. The Linguistic Review 32(2): 277-332. doi.org10.1515/tlr-2014--0024

Giannakidou, Anastasia \& Melita Stavrou. 1999. Nominalization and ellipsis in the Greek DP. Linguistic review 16: 295-331.

Giusti, Giuliana. 2015. Nominal syntax at the interfaces. A comparative analysis of languages with articles. Cambridge: Cambridge Scholars Publishing.

Guardiano, Cristina \& Melita Stavrou. 2019. Adjective-noun combinations in Romance and Greek of Southern Italy. Polydefiniteness revisited. Journal of Greek Linguistics 19(1): 3-57. doi.org/10.1163/15699846-01901001

Heim, Irene. 1982. The semantics of definite and indefinite noun phrases. Doctoral dissertation, University of Massachussetts at Amherst.

Higginbotham, James. 1985. On semantics. Linguistic inquiry 16(4): 547-594.

Holton, David, Peter Mackridge \& Irene Philippaki-Warburton. 1997. Greek: A comprehensive grammar of the modern language. London: Routledge.

Horrocks, Geoffrey \& Melita Stavrou. 1986. Mia proti prosengisi ke erminia ton epithetikon prosdiorismon sta Nea Ellinika (A first approach and interpretation of adjectival modification in Modern Greek). Studies in Greek linguistics. Proceedings of the the 7 th annual meeting of the Department of Linguistics, 109-116. Thessaloniki: Kyriakidis.

Horrocks, Geoffrey \& Melita Stavrou. 1987. Bounding theory and Greek syntax: Evidence for wh-movement in NP. Journal of Linguistics 23: 79-108.

Ioannidou, Alexandra \& Marcel den Dikken. 2006. P-drop, D-drop, D-spread. Paper presented at Syracuse University, April 28, 2006.

Ionin, Tania \& Eve Zyzik. 2014. Judgment and interpretation tasks in second language research. Annual review of Applied Linguistics 34: 37-64. doi.org/10.1017/So267190514 000026

Ivanova, Iva, Martin J. Pickering, Holly P. Branigan, Janet F. McLean \& Albert Costa. 2012. The comprehension of anomalous sentences: Evidence from structural priming. Cognition 122: 193-209. doi.org/10.1016/j.cognition.2011.10.013 
Jackendoff, Ray. 1977. X-bar Syntax. Cambridge, MA: MIT Press.

Juzek, Thomas. 2016. Acceptability judgement tasks and grammatical theory. Doctoral dissertation, University of Oxford.

Kaschak, Michael \& Arthur Glenberg. 2004. This construction needs learned. Journal of Experimental Psychology. General 133(3): 450-467. doi.org/10.1037/oog6-3445.133 $.3 .45^{\circ}$

Kayne, Richard. 1994. The antisymmetry of syntax. Cambridge, MA: Miт Press.

Kolliakou, Dimitra. 1995. Definites and possessives in Modern Greek: An HPSG syntax for noun phrases. Doctoral dissertation, University of Edinburgh.

Kolliakou, Dimitra. 2004. Monadic definites and polydefinites: Their form, meaning and use. Journal of Linguistics 40: $263-323$.

Larson, Richard. 1995. Olga is a beautiful dancer. Paper presented at Linguistic Society of America Annual Meeting, New Orleans, January 1995.

Larson, Richard. 1998. Events and modification in nominals. In Proceedings from Semantics and Linguistic Theory (SALT) VIII, ed. by Devon Strolovitch \& Aaron Lawson, 145-168. Ithaca, NY: Cornell University Press.

Lekakou, Marika \& Kriszta Szendrői. 2007. Eliding the noun in close apposition, or Greek polydefinites revisited. UCL Working Papers 19: 129-154.

Lekakou, Marika \& Kriszta Szendrői. 2012. Polydefinites in Greek: Ellipsis, close apposition and expletive determiners. Journal of Linguistics 48: 107-149. doi.org/10.1017/ Soo22226711000326

Mackridge, Peter. 1985. The Modern Greek language. A descriptive analysis of Standard Modern Greek. Oxford: Clarendon Press.

Manolessou, Io. 2000. Greek Noun Phrase structure: A study in syntactic evolution. Doctoral dissertation, University of Cambridge.

Marmaridou, Angeliki Sophia. 1984. Study of reference, attribution and genericness in the context of English and their grammaticalization in Modern Greek noun phrases. Doctoral dissertation, University of Cambridge.

Panagiotidis, Phoevos. 2002. Pronouns, clitics and empty nouns. Pronominality and licensing in syntax. Amsterdam: John Benjamins.

Panagiotidis, Phoevos \& Theodoros Marinis. 2011. Determiner spreading as DPpredication. Studia Linguistica 65(3): 268-298. doi.org/10.1111/j.1467--9582.2011.01186.x

Partee, Barbara. 1987. Noun Phrase interpretation and type-shifting principles. Studies in Discourse Representation Theory and the Theory of Generalized Quantifiers, ed. by Jeroen A. Groenendijk \& Martin J.B. Stockhof, 115-143. Dordrecht: Foris.

Pereltsvaig, Asya. 2007. Copular sentences in Russian. A theory of intra-clausal relations. Dordrecht: Springer.

Pesetsky, David. 1987. Wh-in-situ: Movement and unselective binding. In The representation of (in)definiteness, ed. by Eric Reuland \& Alice ter Meulen, 98-129. Cambridge, MA: MIT Press. 
Poesio, Massimo. 1994. Weak definites. Proceedings of Semantics and Linguistic Theory $(S A L T) I V$, ed. by Mandy Harvey \& Lynn Santelmann, 282-299. journals.linguistic society.org/proceedings/index.php/SALT/issue/view/105

Roussou, Anna. 1994. The syntax of complementisers. Doctoral dissertation, University College London.

Rouveret, Alain. 2011. Resumptive pronouns at the interfaces. Amsterdam: John Benjamins.

Russell, Bertrand. 1905. On denoting. Mind 14: 479-493.

Schütze, Carson \& Jon Sprouse. 2014. Judgment data. Research methods in linguistics, ed. by Robert J. Podesva \& Devyani Sharma, 27-5o. Cambridge: Cambridge University Press. doi.org/10.1017/cbo9781139013734.004

Sharvy, Richard. 1980. A more general theory of definite descriptions. The Philosophical Review 89(4): 607-624.

Stavrou, Melita. 1995. Epexegesis vs. Apposition. Scientific Yearbook of the Classics Dept. Thessaloniki: Aristotle University of Thessaloniki.

Stavrou, Melita. 2012. Postnominal adjectives in Greek indefinite noun phrases. Functional heads: The cartography of syntactic structures, ed. by Laura Brugé, Anna Cardinaletti, Giuliana Giusti, Nicola Munaro \& Cecilia Poletto, 379-394. New York: Oxford University Press. doi.org/10.1093/acprof:oso/9780199746736.003.0029

Stavrou, Melita. 2013. The fine(r) ingredients of adjectival modification in Greek: The Romance connection. Paper presented at Incontro di Grammatica Generativa (IGG) 39, Modena and Reggio Emilia, February 21-23, 2013.

Tsakali, Vina. 2008. Similarities in the interpretation of doubling constructions. Paper presented at the 29th Meeting of the Department of Linguistics of the Aristotle University of Thessaloniki.

Tsiakmakis, Evripidis, Joan Borràs-Comes \& M. Teresa Espinal. (to appear). Greek polydefinites at the interfaces. Proceedings of Linguistic Evidence 2020.

Tsimpli, Ianthi Maria. 1995. Focusing in Modern Greek. Discourse configurational languages (Oxford studies in comparative syntax), ed. by Katalin Kiss, 176-206. Oxford: Oxford University Press.

Velegrakis, Nikolaos. 2011. The syntax of Greek polydefinites. Doctoral dissertation, University College London.

Wellwood, Alexis, Roumyana Pancheva, Valentine Hacquard \& Colin Phillips. 2018. The anatomy of comparative illusion. Journal of Semantics 35(3): 543-583. doi.org/10 $.1093 /$ jos/ffyo14 